\title{
IDENTIFIKASI RESIKO INVESTOR DALAM INVESTASI JALAN TOL
}

\author{
Adhi Purnomo, Beta Proton Dalijus
}

\begin{abstract}
Abstrak
Dengan dicanangkannya percepatan pembangunan infrastruktur yang antara lain juga mencakup pembangunan $1600 \mathrm{~km}$ jalan tol dalam 5 tahun kedepan, pemerintah sudah melakukan perombakan pada regulasi yang mempermudah untuk berinvestasi bisnis jalan tol yang bankable dengan ditetapkannya Undang-Undang No. 38 tahun 2004 tentang Jalan dan Peraturan Pemerintah No. 15 tahun 2005 tentang Jalan Tol.

Konsep yang mendasari jalan tol adalah suatu konsep pendanaan dimana dana pembangunan jalan tol sepenuhnya diperoleh dari pemakai jalan tol melalui pengenaan tarif tol. Sedangkan investor dibantu lembaga-lembaga pendanaan dalam hal ini berfungsi sebagai "jembatan" agar jalan tol yang bersangkutan dapat diwujudkan dan menghasilkan pendapatan. Industri jalan tol merupakan proyek yang sangat dipengaruhi risiko dan ketidakpastian dimana timbulnya risiko dan ketidakpastian akan mempengaruhi investor merencanakan investasi proyek jalan tol.

Penelitian ini dilakukan untuk mendapatkan faktor-faktor utama dari sekian banyak faktor risiko yang mempengaruhi risk response planning investor jalan tol untuk memutuskan berinvestasi jalan tol di Indonesia.

Setelah melakukan pengujian data maka hasil penelitian didapat bahwa faktor internal lebih dominan dari pada faktor eksternal, dimana prioritas faktor berdasarkan kriteria yaitu identifikasi risiko dan risk attitute memberikan kontribusi hasil yang signifikan. Sedangkan urutan prioritas faktor berdasarkan subkritera adalah; variabel penentuan besaran tarif, perkiraan biaya konstruksi, operasi, dan pemeliharaan, perkiraan volume lalu lintas, tingkat pengembalian investasi, masa konsesi, kematangan dalam mengambil keputusan, profesionalitas sikap, dan keterlambatan penyelesaian proyek.
\end{abstract}

Kata kunci : Investor Jalan Tol, Respon Risiko, Risk Response Planning

\section{PENDAHULUAN}

Pembangunan jalan tol di Indonesia telah dimulai sejak 26 tahun lalu, namun total panjang jalan tol yang telah dibangun hingga saat ini baru mencapai 570 kilometer $(\mathrm{km})$. Malaysia yang baru memulai pembangunan jalan tol 20 tahun lalu, telah berhasil membangun jalan tol sepanjang $1.230 \mathrm{~km}$. Di Cina, panjang jalan tol mencapai lebih dari $100.000 \mathrm{~km}$ dan jalan arteri sekitar 1,7 juta km dengan tingkat kepadatan jalan $1.384 \mathrm{~km} / 1$ juta penduduk. Sedangkan di Indonesia tingkat kepadatan jalan hanya

Adhi Purnomo, MT

Staf Pengajar Jurusan Teknik Sipil

Fakultas Teknik

Universitas Negeri Jakarta, 13220
Beta Proton Dalijus, MT Alumnus Jurusan Manajemen Konstruksi Universitas Indonesia, 
$126 \mathrm{~km} / 1 \mathrm{juta}$ penduduk. Rendahnya tingkat pembangunan jalan tol di Indonesia disebabkan antara lain oleh : (1) belum adanya perencanaan sistem jaringan jalan tol yang dapat mendorong terjadinya kompetisi antar operator; (2) belum adanya regulasi, tata cara dan aturan yang mengatur penyelenggaraan jalan tol oleh pihak swasta; dan (3) belum adanya prosedur untuk pemilihan investor yang kompetitif, pengadaan lahan, cost sharing, masa konsesi, dan dasar pembagian pendapatan [Bappenas, 2005].

Dalam upaya mengatasi permasalahan pembangunan jalan tol, beberapa kendala mendasar dicoba diatasi melalui revisi Undang-Undang No. 13/1980 menjadi UndangUndang No. 38/2004 tentang Jalan dan ditetapkannya Peraturan Pemerintah No. 15/2005 tentang Jalan Tol. Perubahan penting dalam pengaturan jalan tol terutama adalah kemudahan proses investasi yang semula oleh Presiden menjadi cukup oleh Menteri PU. Di dalam UU No. 38/2004 dan PP No.15/2005 diatur bagaimana kepastian tarif awal, yaitu pada saat proses negosiasi investor dengan regulator sesuai hasil pelelangan yang disurvai. Penyesuaian diadakan setiap 2 tahun sekali berdasarkan inflasi. Kemudian diatur juga pemisahan antara peran pengatur (regulator) dan pengusahaan (operator) melalui pembentukan Badan Pengatur Jalan Tol (BPJT)

\section{Peran Investor Dalam Pengembangan Jalan Tol}

Tantangan yang dihadapi Pemerintah saat ini adalah menyediakan sarana dan prasarana transportasi sesuai kebutuhan yang terus meningkat sejalan dengan pertumbuhan penduduk dan ekonomi. Pemerintah berkewajiban menyediakan dan menjamin terselenggaranya transportasi yang aman, lancar, dan efisien. Namun, karena keterbatasan anggaran Pemerintah, pembangunan prasarana dan fasilitas transportasi tidak dapat secara terus menerus mengikuti trend permintaan yang tumbuh pesat ini.

Salah satu cara yang dapat dilakukan untuk mengatasi keterbatasan anggaran ini adalah dengan membangun jalan tol yang dibiayai melalui pembayaran tarip tol oleh penggunanya. Dampak permintaan jasa transportasi yang besar baik dari sisi ekonomi, lingkungan, dan sosial melahirkan berbagai kebijakan transportasi terutama dari sisi ekonomi yang dapat memberikan perbaikan, nilai tambah, dan optimalisasi terhadap sarana dan prasarana yang ada. Pada gambar 1. menunjukkan berbagai kebijakan yang dapat diambil dalam memberikan dampak ekonomi yang luas bagi pengembangan sarana maupun prasarana dimana salah satunya melalui kebijakan 'road pricing' yang dapat 
memberikan pengaruh secara langsung dari sisi pengunaan ruang yang lebih optimal (infrastructure use), kemudahan Akses ke berbagai tempat (infrastructure access), dan tingkat penggunaan ruang jalan yang lebih baik dan efisien (road space use).

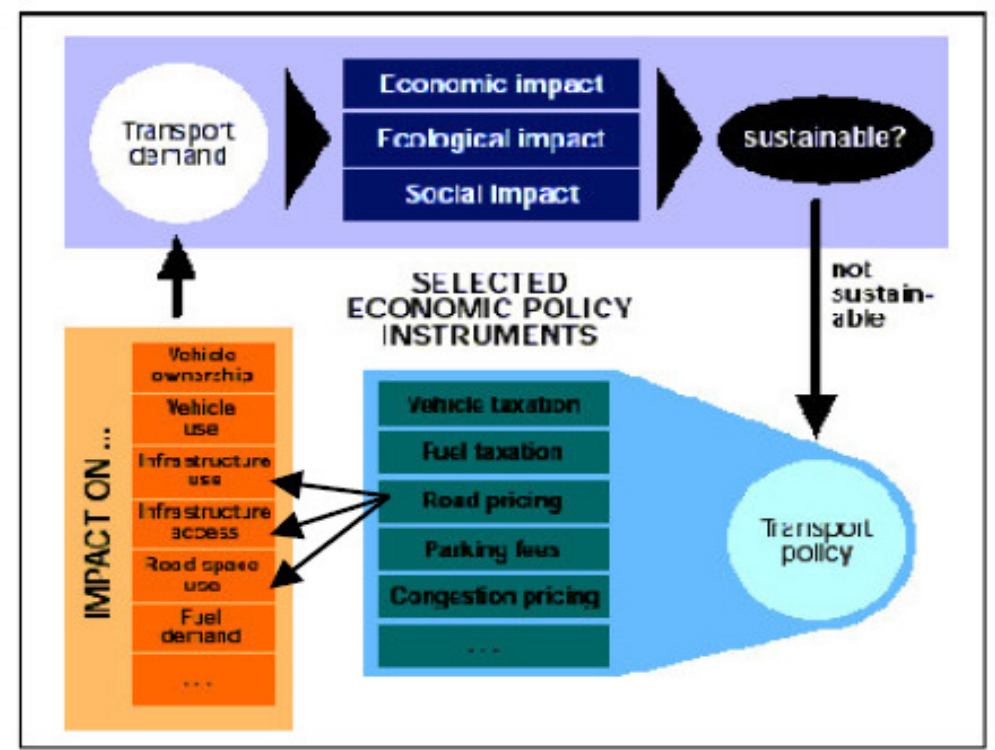

Gambar 1 : Instrumen Kebijakan Ekonomi [Dephub., 2002]

Konsep jalan tol adalah suatu konsep pendanaan dimana dana pembangunan jalan tol sepenuhnya diperoleh dari pemakainya melalui pengenaan tarif tol. Peran swasta dibantu lembaga-lembaga pendanaan dalam hal ini berfungsi sebagai "jembatan" agar jalan tol yang bersangkutan dapat diwujudkan dan menghasilkan pendapatan. Jalan tol yang memiliki kelayakan finansial yang baik (volume lalu lintas awal di atas 15.000/hari) sepenuhnya dapat didanai dari pendapatan tol. Sementara jalan tol yang belum sepenuhnya layak secara finansial dapat didanai dengan suatu pola hibrid dimana pemerintah membiayai sebagian (subsidi) sedemikian sehingga porsi pembiayaan sektor swasta tetap berada dalam batas kelayakan finansial, artinya pembagian risiko bagi sektor swasta dapat dikembalikan dari pendapatan jalan tol yang bersangkutan [Frans Sunito, 2005]. 


\section{Investasi Pembiayaan Jalan tol}

Tugas utama regulator adalah menjamin terjadinya kompetisi yang sehat dan harga / tarip berada dalam marginal cost. Regulator juga harus menjamin bahwa operator dari sektor swasta mempunyai insentif yang cukup untuk investasi dalam pelayanan yang 'socially desirable', meskipun tidak 'profitable'. Dari sudut swasta sebagai investor memandang bahwa biaya yang dikeluarkannya harus kembali dalam bentuk nilai uang (dan berbagai kompensasinya). Dalam hal ini komponen biaya dianggap sebagai jumlah nilai uang yang harus dikeluarkan oleh pengusaha untuk biaya konstruksi, biaya operasi, dan biaya pemeliharaan sistem yang dikelolanya. Sedangkan komponen pembiayaan jalan tol diperoleh dari jumlah nilai uang yang mereka peroleh dari pengguna fasilitas jalan tol, serta kemungkinan kompensasi lainnya (hak penggunaan lahan, hak pengusahaan di area layanan, program konsesi, dan lain-lain).

Salah satu bentuk kompensasi cukup menarik untuk dikaji dan berkaitan dengan risiko yang dihadapi investor adalah program konsesi. Dengan konsesi ini diharapkan minat swasta untuk ikut berpartisipasi lebih besar karena adanya aturan kebijakan dan hukum yang mendasari pemberian konsesi tersebut. Konsesi ini mendorong munculnya perusahaan yang sehat untuk ikut berpartisipasi dalam pembiayaan jalan tol secara aktif.

Struktur program konsesi sebagaimana gambar di bawah ini.

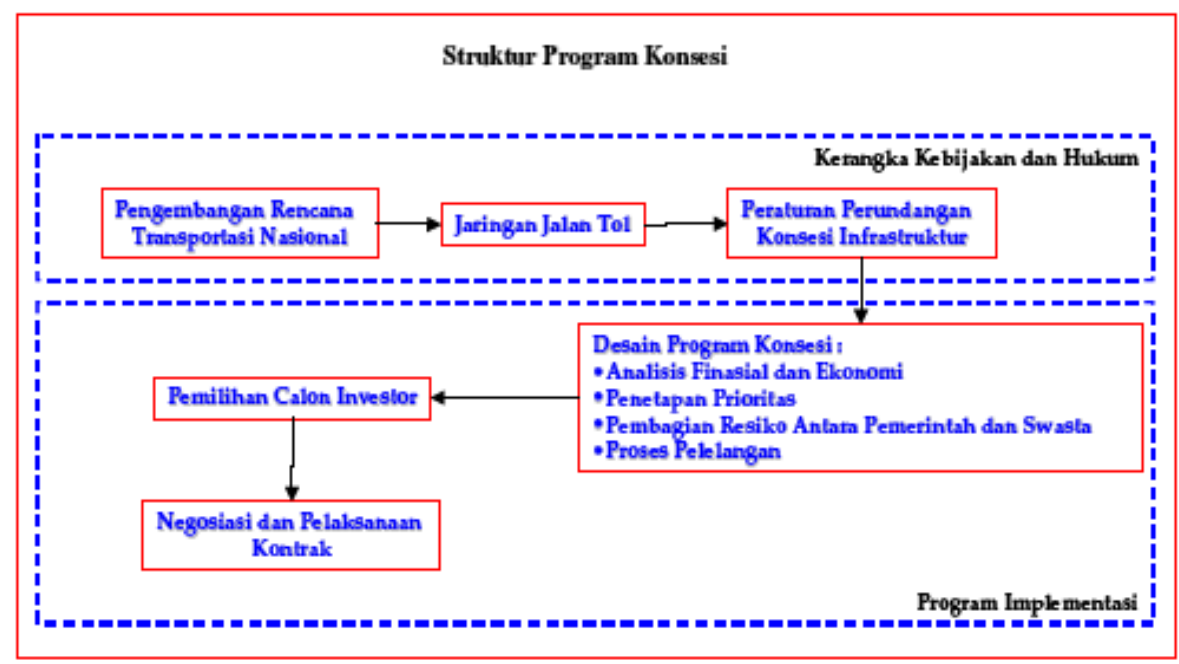

Gambar 2 : Struktur Program Konsesi

Sumber : Jasa Marga, 2000

Pemerintah biasanya menetapkan masa program konsesi untuk investasi jalan tol selama 35 tahun dan hal ini berdasarkan pengembalian investasi, pendapatan tol terhadap besaran penetapan tarip awal tol yang sudah mempertimbangkan daya beli masyarakat. 
Besaran tarip awal tol yang ditetapkan Pemerintah / regulator berkisar Rp. 400 s/d Rp. 500 per km dengan masa konsesi 35 tahun, hal ini menyulitkan investasi pembiayaan yang akan dilakukan investor. Adapun mekanisme penetapan tarip awal jalan tol, seperti pada gambar di bawah ini :

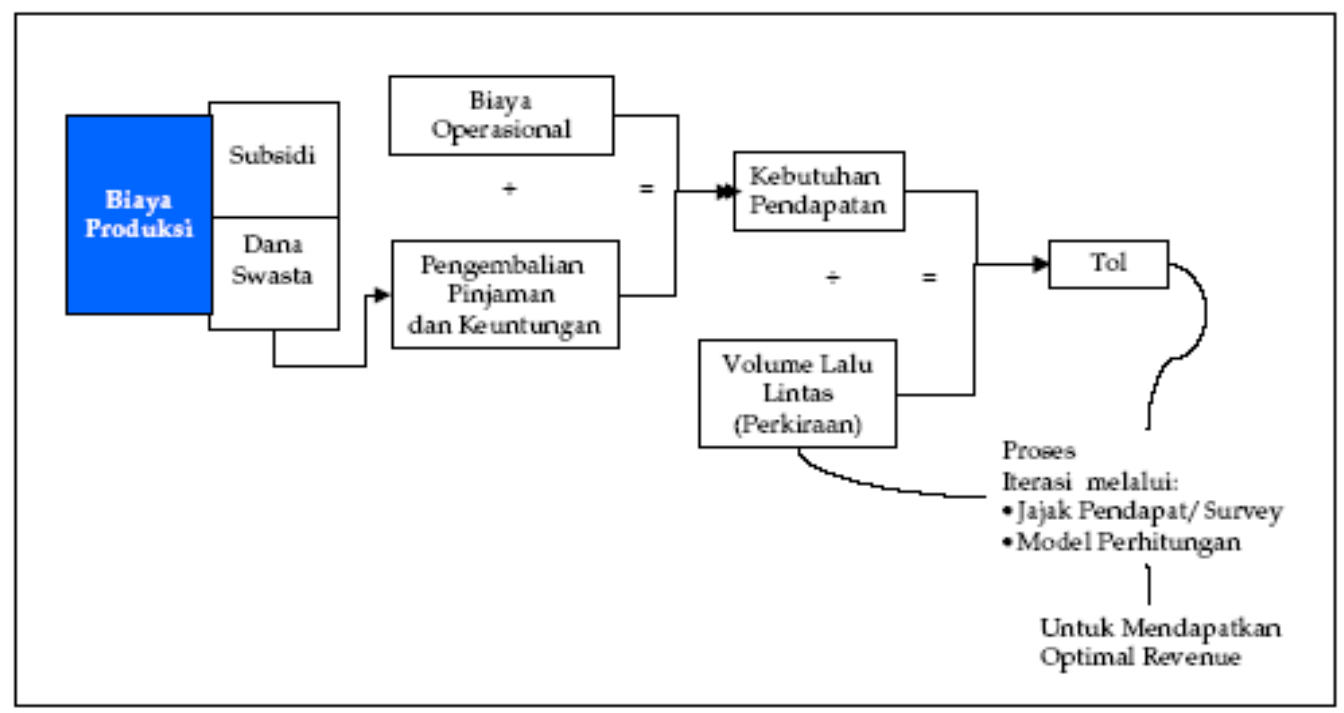

Gambar 3 : Mekanisme Penetapan Tarif Awal Jalan Tol

Sumber : Jasa Marga, 2000

Gambaran investasi biaya dari jalan tol yang akan dibangun harus sudah tersusun dengan mempertimbangkan aspek ekonomi dari proyek itu dilengkapi dengan konsep operasional dari jalan tol tersebut, jadwal waktu pelaksanaan pekerjaan, biaya operasi yang dibutuhkan untuk menjalankan proyek tersebut serta perhitungan ekonomis dan finansial yang dilengkapi dengan besaran tarip yang akan ditetapkan. Disamping itu struktur pembiayaan jalan tol tersebut juga harus jelas terhadap distribusi risiko yang mungkin terjadi.

Dalam investasi bisnis jalan tol berkaitan dengan pembiayaan jalan tol, investor akan menghadapi berbagai risiko. Risiko yang dihadapi oleh investor meliputi hal-hal sebagai berikut:

1. Tambahan biaya pembangunan karena tidak atau belum diperhitungkan terlebih dahulu seperti:

- Persetujuan rencana; 
- Perubahan mesin konstruksi, pekerjaan tanah dan struktur bangunan disekitar yang terganggu;

- Pembebasan tanah

- Tertundanya proyek.

2. Perkiraan arus lalu lintas yang lebih rendah daripada yang direncanakan berdampak pada perkiraan pendapatan.

3. Kerusuhan, huru-hara ataupun perang (force majeur)

4. Kebijakan tarip yang diberlakukan

- Rumusan penyesuaian tarip yang akan diberlakukan,

- Regulasi mengenai jalan tol,

Kepastian bahwa kebijakan tarip tidak dirubah, untuk itu perlu ada penyajian/kontrak jangka panjang.

\section{Sikap Investor Mengambil Keputusan (Risk Attitude)}

Risk attitude adalah sikap untuk mengambil keputusan berkaitan dengan adanya risiko [Flanagan, 1993]. Sikap investor dalam mengambil keputusan melakukan aktifitas bisnis merupakan variabel yang dapat diukur dengan suatu formula tertentu. Setiap pihak / investor dapat mengambil keputusan yang berbeda-beda dalam menghadapi masalah yang sama tergantung pada waktu, situasi, kondisi, pengalaman, dan lingkungannya [Charette, 1989].

Pada investasi proyek jalan tol, investor sulit untuk menyikapi keputusan terhadap risiko yang akan terjadi. Dimana dibandingkan investasi harta lancar, tingkat risiko yang dihadapi investor dalam investasi proyek lebih besar. Risiko yang besar tadi tidak hanya karena besarnya jumlah dana yang terikat, melainkan juga karena panjangnya jangka waktu yang diperlukan untuk memetik keuntungan, yang diperlukan untuk mengembalikan dana yang sudah diinvestasikan [Siswanto S, 2000].

Investor bisnis jalan tol perlu menyikapi risiko pembiayaan investasi yang dihadapi, salah satu diantaranya terhadap penentuan tarip awal jalan tol. Hal ini sangat berpengaruh dalam pengembalian dana investasi, semakin tidak ada kepastian / terukur penetuan tarip akan semakin besar risiko yang akan dihadapi investor. Komponen penting dari ketidakpastian penetuan tarip awal jalan tol adalah perkiraan volume lalu lintas yang lebih 
rendah, masa konsensi, perkiraan suku bunga bank, dan peran regulator yang menentukan standar tarip.

\section{Risiko Pembiayaan Proyek Jalan Tol}

Mengingat proyek jalan tol merupakan proyek jangka panjang dan sangat terpengaruh oleh fluktuasi tingkat bunga, inflasi, dan nilai tukar rupiah, termasuk devaluasi, penyesuaian tarif setiap periode tertentu sangat diperlukan. Masalah pokok dalam industri jalan tol yang mempengaruhi tingkat kepastian (risiko) investasi adalah masalah tarif tol, lahan dan penjaminan / kompensasi apabila terjadi default baik oleh investor maupun oleh pemerintah. Ketiga aspek di atas tidak berada dalam kendali investor sehingga seyogyanya pemerintah mengambil alih risiko-risiko ini, karena Pemerintahlah yang dapat mengendalikan hal-hal tersebut. Risiko lainnya dalam investasi jalan tol seperti biaya konstruksi, biaya bunga, volume lalu lintas, operasi dan pemeliharaan adalah sepenuhnya risiko investor. Oleh karena itu, kerangka regulasi pemerintah mengenai formula perhitungan penentuan dan penyesuaian tarif yang adil dan transparan menjadi sangat penting untuk dirumuskan. Perlu disadari bahwa besaran tarif merupakan salah satu faktor penentu utama dalam pengambilan keputusan layak atau tidaknya suatu proyek infrastruktur. Pengalaman di negara kita, penyesuaian tarip selalu tidak tegas, bahkan setiap akan dilakukan penyesuaian tarip selalu mendapatkan protes keras dari masyarakat serta badan legislatif, yang pada akhirnya penyesuaian tarip ditentukan bukan berdasarkan pertimbangan finansial, tetapi lebih pada pertimbangan politis. Oleh karena itu, bila kondisi semacam ini tidak berubah, upaya peningkatan partisipasi swasta dalam pembangunan infrastruktur di Indonesia akan sulit untuk direalisasikan.

Kunci keberhasilan untuk menarik investor dalam investasi infrastruktur dalam hal ini jalan tol yang sifatnya jangka panjang adalah alokasi risiko yang tepat, dimana risiko dipikul oleh pihak yang paling dapat mengendalikannya. Perlu pula disadari bahwa lahan maupun jalan tol yang dibangun oleh investor adalah tetap milik pemerintah, sementara investor hanya mendapat hak pengusahaan selama masa konsesi yang berkisar antara 30-40 tahun. Seluruh asset yang diinvestasikan oleh investor langsung menjadi milik pemerintah sejak hari pertama dibangun, sehingga tidak mungkin dijadikan agunan. 


\section{METODOLOGI}

Teknik pengumpulan data yang akan dilakukan adalah dengan cara studi kasus baik melalui wawancara langsung maupun dengan pengisian kuesioner yang telah disusun sebelumnya. Data yang diharapkan berupa data primer, berbentuk hasil wawancara dan isian kuesioner.

Penyebaran kuestioner dilakukan untuk mengetahui permasalahan aktual yang dihadapi oleh investor terkait dalam berinvestasi jalan tol, dan identifikasi risiko yang mempengaruhi risk response planning yang dilakukan terhadap setiap permasalahan yang ada sebagai upaya pengelolaan investasi jalan tol.

Pengambilan data primer ini menggunakan kuesioner yang dirancang secara khusus disesuaikan dengan format inputan Expert Choice dan disebarkan kepada responden tertentu dengan harapan para responden menjawab pertanyaan - pertanyaan yang ada sesuai dengan tujuan penelitian.

\section{PEMBAHASAN}

Sebelum memulai dan memutuskan untuk berinvestasi jalan tol, investor harus melakukan proses risk response planning yang bertujuan mengembangkan pilihan-pilihan dan penentuan tindakan untuk mendapatkan kesempatan yang besar serta memperkecil ancaman terhadap sasaran, yaitu berinvestasi jalan tol. Dengan cara, investor melakukan identifikasi risiko, mendefinisikan dampak dan probabilitas risiko, mengkaji kemampuan dalam menangani risiko tersebut, kemudian terakhir menetapkan status risiko tersebut. Dengan melakukan risk response planning yang efektif, investor akan secara langsung menentukan apakah risiko terhadap sasaran (goal) bertambah atau berkurang. Bertambah besar tingkatan risiko yang akan diterima investor mengakibatkan sumber daya dan sumber dana untuk menanggulanginya menjadi lebih besar sehingga investor cenderung untuk mengalihkan risiko tersebut dan memimalkannya dari kerugian yang mungkin akan timbul. Proses risk response planning membutuhkan pemilihan respon risiko (risk response) yang sesuai dengan tingkatan risiko yang diterima, dimana pemilihan respon risiko yang terbaik sangat diperlukan investor. 
Identifikasi Resiko yang memperngaruhi risk response planning investor jalan tol dalam berinvestasi jalan tol dapat digambarkan sebagai berikut :

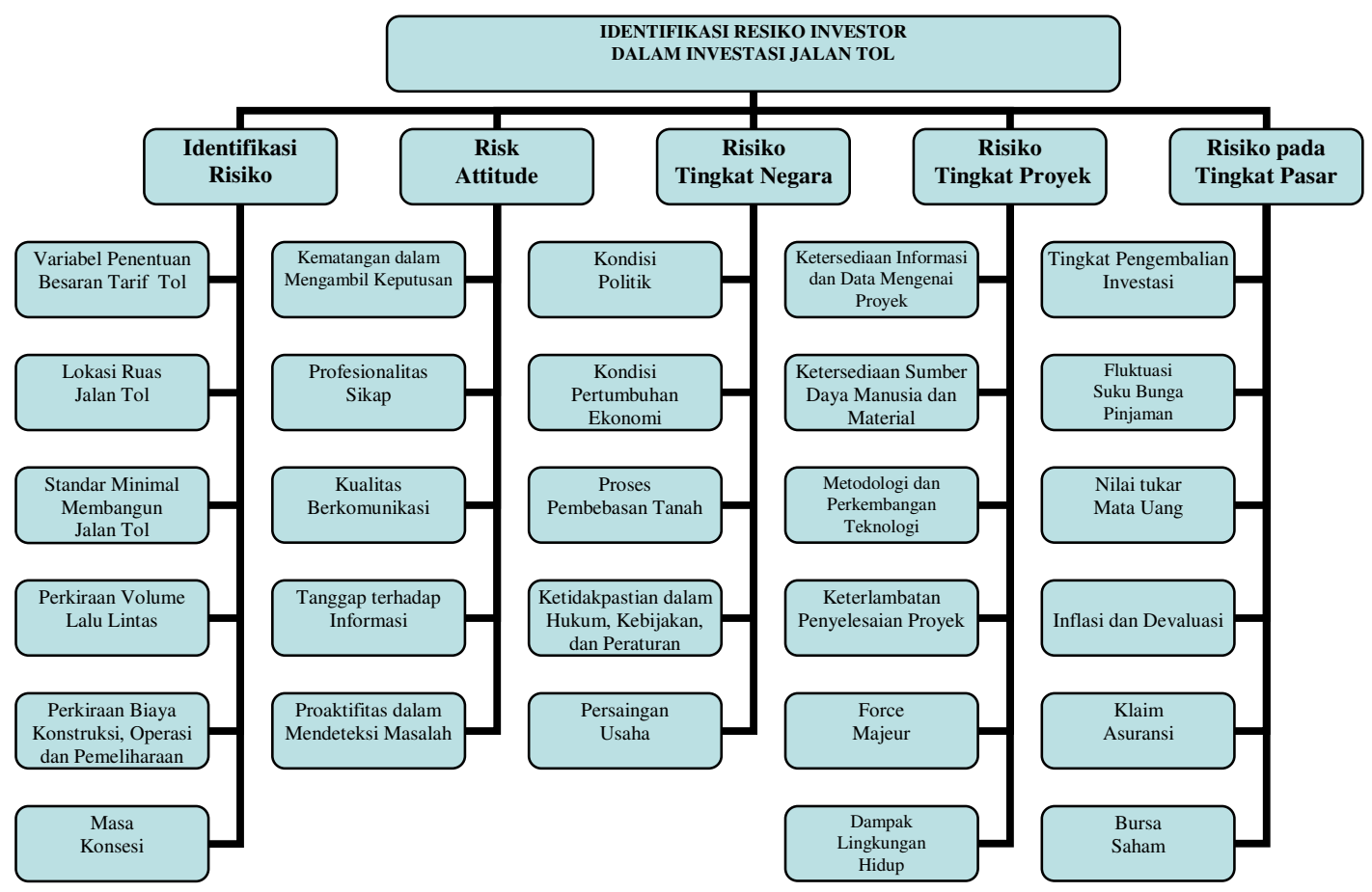

Gambar 4 : Identifikasi resiko investor dalam investasi jalan tol

Dari data hasil pengolahan data maka diperoleh faktor-faktor utama yang mempengaruhi risk response planning investor jalan tol untuk memutuskan berinvestasi jalan tol di Indonesia. adalah sebagai berikut :

1. Variabel Penentuan Besaran Tarif Tol, dari kriteria Identifikasi Risiko.

Hal ini jelas bahwa potensi pendapatan swasta (investor jalan tol) khususnya yang bersumber dari tarif perlu diformulasikan secara cermat agar kepastian investasi menjadi tinggi (risiko investasi menjadi rendah). Pada dasarnya penentuan tarif harus menutup seluruh biaya yang ditanggung investor (full cost recovery). Tarif juga merupakan komponen utama dalam penawaran yang diajukan oleh peserta lelang (sebelum investor memulai investasi). Sedangkan variabel penentuan besaran tarif tol merupakan dasar yang signifikan dalam penentuan besaran tarif awal tol sebelum melakukan investasi. Variabel penentuan besaran tarif tol adalah semua yang berkenaan dengan analisa perhitungan tarif awal tol diantaranya; besar keuntungan 
biaya operasi kendaraan (BKBOK), kemampuan membayar (ability to pay/ATP), dan kelayakan investasi.

2. Perkiraan Biaya Konstruksi, Operasi, dan Pemeliharaan, dari kriteria Identifikasi Risiko.

Investasi jalan tol menyerap dan mengikat dana yang secara absolut atau dalam persentase sangat besar jumlahnya. Oleh karena itu apabila terjadi kesalahan dalam perencanaan, dampak negatif harus diderita investor cukup lama dan mungkin berkepanjangan selama life cycle selama masa investasi. Investor menganggap bahwa komponen biaya sebagai jumlah nilai uang yang harus dikeluarkan untuk biaya konstruksi, biaya operasi, dan biaya pemeliharaan dari investasi yang dikelola. Selain itu pertimbangan yang lain adalah investor juga harus menyediakan modal sendiri yang besarannya sudah ditentukan oleh regulator dalam hal ini BPJT dari total biaya investasi (biaya konstruksi, biaya operasi, dan biaya pemeliharaan yang harus ditanggung investor selama masa konsesi). Dan berarti investor jalan tol selain harus kuat dalam ekonomi juga kuat dalam finansialnya

3. Perkiraan Volume Lalu Lintas, dari kriteria Identifikasi Risiko.

Perkiraan volume lalu lintas merupakan komponen penting terhadap besaran tarif dan penerimaan/pendapatan tol. Sumber utama dari penerimaan jalan tol selain besarnya tarif adalah perkiraan volume lalu lintas. Bertambah besar perkiraan volume lalu lintas yang akan menggunakan jalan tol akan meningkat juga penerimaan/pendapatan jalan tol tersebut. Demikian pula sebaliknya jika perkiraan volume lalu lintas yang akan menggunakan jalan tol itu kecil, maka penerimaan/pendapatan jalan tol tersebut akan kecil. Hal ini membuat investor harus lebih cermat dalam menghitung proyeksi volume lalu lintas pada ruas jalan tol yang akan diinvestasi. Investasi jalan tol memiliki kelayakan finansial yang baik adalah mempunyai perkiraan volume lalu lintas awal di atas 15.000 / hari.

4. Tingkat Pengembalian Investasi, dari kriteria Tingkat Pasar Tingkat pengembalian investasi merupakan evaluasi profitabilitas rencana investasi yang memperhitungkan nilai waktu uang. Jadi jelas bahwa keuntungan yang didapat 
oleh investor jalan tol harus memperhitungkan lamanya uang yang ditanamkan, biasanya investasi jalan tol adalah investasi jangka panjang (20 s/d 30 tahun). Tingkat pengembalian investasi sering juga disebut internal rate of return (IRR) dan the discounted rate of return atau faktor diskonto yang apabila dipergunakan untuk mendiskonto seluruh cash inflows dan salvage value, akan menghasilkan jumlah present value yang sama dengan jumlah yang sudah investasikan. Tingkat pengembalian investasi jalan tol ini menggambarkan bahwa persentase keuntungan investor senyatanya akan diperoleh dari investasi modal yang sudah direncanakan. Tingkat pengembalian investasi yang baik adalah dimana nilai persen IRR-nya lebih besar dari nilai persen suku bunga bank. Dan biasanya badan pengatur jalan tol / BPJT akan menginformasikan pada investor mengenai berapa besar IRR (hasil studi BPJT) masing-masing ruas tol yang akan ditenderkan.

5. Masa Konsesi, dari kriteria Identifikasi Risiko.

Lamanya waktu investasi berdasarkan pengembalian investasi dan pendapatan jalan tol terhadap besaran penetapan tarif awal tol dan tarif tol penyesuaian yang sudah mempertimbangkan daya beli masyarakat. Masa konsensi sering juga disebut payback period, dengan payback period yang cukup lama yaitu berkisar $20 \mathrm{~s} / \mathrm{d} 30$ tahun, banyak investor jalan tol mempertimbangkannya. Prinsip dasar payback period adalah waktu yang diperlukan investasi untuk mengumpulkan dana intern guna mengembalikan seluruh dana yang telah diinvestasikan. Apabila payback period lebih pendek dari standar payback period yang ditetapkan investor pada usulan rencana investasi, maka dapat dipertimbangkan. Sedangkan apabila payback period lebih panjang usulan akan ditolak. Atau dengan kata lain semakin pendek jangka waktu payback period, semakin menarik pula rencana investasi yang akan dilakukan.

6. Kematangan dalam Mengambil Keputusan, dari kriteria Risk Attitute.

Kematangan memutuskan berlandaskan pada sesuatu yang sudah dipertimbangkan dengan matang. Disini terlihat bahwa peran pelaku manajemen risiko investor jalan tol dalam menetapkan kebijakan dan pengawasan risiko merupakan hal yang sangat penting. Tingkat kualitas dari pelaku manajemen risiko investor sangat diperlukan 
dalam memutuskan respon risiko apa yang akan dipilih investor, selain itu juga peran direktur dan komisaris yang siap mengeksekusi kebijakan yang sudah dipilih.

7. Profesionalitas Sikap, dari kriteria Risk Attitute.

Ini merupakan suatu sikap yang mengedepankan profesionalitas investor jalan tol dengan pertimbangan-pertimbangan kualitas intelektual dari masing-masing disiplin ilmu untuk menunjang atau mendukung dalam memutuskan berinvestasi jalan tol tol. Manfaat yang didapat investor jalan tol terhadap profesionalitas sikap ini adalah pertimbangan yang akan diputuskan akan membuat percaya diri yang sangat kuat terhadap ancaman risiko, setelah memutuskan sikap ikut berinvestasi dan tidak ikut berinvestasi.

8. Keterlambatan Penyelesaian Proyek, dari kriteria Tingkat Proyek.

Keterlambatan atau penundaan (delay) pembangunan jalan tol yang tidak dapat dimanfaatkan sesuai dengan rencana, sehingga menyebabkan beberapa kegiatan yang mengikuti menjadi tertunda atau tidak dapat diselesaikan tepat sesuai dengan jadual yang telah direncanakan. Hal ini bila terjadi dalam masa investasi akan membuat usulan rencana investasi jalan tol yang sudah direncanakan bertambah beban biaya. Dan jika keterlambatan berlarut-larut proses investasi jalan tol akan terhenti dan berdampak kepada pencabutan perjanjian pengguasaan jalan tol (PPJT) oleh BPJT.

\section{KESIMPULAN}

Kesimpulan yang dapat diambil dari penelitian ini bahwa faktor utama yang mempengaruhi risk response planning investor jalan tol untuk memutuskan berinvestasi jalan tol di Indonesia adalah sebagai berikut :

1. Variabel Penentuan Besaran Tarif Tol, dari kriteria Identifikasi Risiko.

2. Perkiraan Biaya Konstruksi, Operasi, dan Pemeliharaan, dari kriteria Identifikasi Risiko.

3. Perkiraan Volume Lalu Lintas, dari kriteria Identifikasi Risiko.

4. Tingkat Pengembalian Investasi, dari kriteria Tingkat Pasar

5. Masa Konsesi, dari kriteria Identifikasi Risiko. 
6. Kematangan dalam Mengambil Keputusan, dari kriteria Risk Attitute.

7. Profesionalitas Sikap, dari kriteria Risk Attitute.

8. Keterlambatan Penyelesaian Proyek, dari kriteria Tingkat Proyek.

\section{DAFTAR PUSTAKA}

A Guide to the Project Management Body of Knowledge 2000 Edition. Project Management Institute. Newton Square, Pennsylvania USA.

Anbari, Frank T. (2003). Earned Value Project Management Method and Extentions. Project Management Journal. Vol.34, No.4.ABI/INFORM Global.

Asiyanto (2005). Contruction Project Cost Management. Penerbit PT. Pradnya Paramita, Jakarta.

Bajaj, D. (2001). Risk Response and Contingency Strategies Among Contractors in Sydney, Australia. AACE International Transaction. ABI/INFORM Global.

Bender, William J. \& Ayyub, Bilal M. (2001). Risk-Based Cost Control for Construction. AACE International Transaction. ABI/INFORM Global.

Blanchard, Benjamin, S. \& Fabrycky, Walter, J. (2000). Systems Engineering And Analysis. Prentice Hall International Series, Third Edition, USA.

Charette, Robert N. (1989). Software Engineering Risk Analysis and Management. McGraw Hill. ISBN 0-070-10661-4.

Djohanputro, Bramantyo, MBA, Ph.D. (2004). Manajemen Risiko Korporat Terintegrasi. Penerbit PPM, Cetakan 2, Jakarta.

El Rayes, K \& Moselhi, O. (2001). Impact of Rainfall on The Productivity of Highway Construction. Journal of Construction Engineering and Management. ASCE. Vol.127, No.2.

Ervianto, Wulfram, I. (2004). Teori Aplikasi Manajemen Proyek Konstruksi. Penerbit Andi, Jogjakarta.

Halpin, D., W. (1998). Construction Management. USA, John Wiley \& Sons, Inc.

Hastak, M. \& Shaked, A. (2000). ICRAM-1 : Model for International Construction Risk Assessment. Journal of Management in Engineering. ASCE. Vol.16, No.1.

Heerkens, Gary, R. (2005). Project Management. PT. Bhuana IImu Populer, Kelompok Gramedia, Jakarta. 
Humphreys, K., K. (1991). Jelen's Cost and Optimization Engineering. Singapore, McGraw Hill, Inc.

Kangari, R. (1995). Risk Management Perception and Trends of U.S. Construction. Journal of Construction Engineering and Management. ASCE.

Kerzner, H. (1998). Project Management - A System Approach to Planning, Scheduling, and Controlling. John Wiley\& Sons, Inc.

Kountur, R. (2006). Management Risiko : Pemahaman Risiko Pentingnya Pengelolaan Risiko, Identifikasi, Pengukuran, Penanganan Risiko, dan Penerapan Manajemen Risiko. Penerbit Abdi Tandur, Jakarta.

Notosoegondo, H. (2005). UU Jalan Nomor 38/2004 Berparadigma Desentralisasi, Non Monopoli, dan Peningkatan Peran Masyarakat dalam Pengembangan Jaringan Jalan. Konferensi Regional Teknik Jalan Ke-8 Wilayah Barat. Batam.

Sutojo, Siswanto. (2000). Pembiayaan Investasi Proyek. PT. Damar Mulia Pustaka, Jakarta.

Peraturan Pemerintah No. 15 (2005), Tentang Jalan Tol.

Widerman, R. Max. \& Fellow, PMI. (1992). Project and Program Risk Management : A Guide to Managing Project Risks and Opportunity. The PMBOK Handbook Series, Vol.6, USA.

Undang-Undang N0.38. (2004), Tentang Jalan.

MSRI, (2003). Tol Road Investment Opportunities in Indonesia, Directorate of Infrastructure Network System.

Sir Alexander Gibb \& Ptns Ltd, (2001). Pre-Feasibility Study Guidelines for Toll Road, Directorate of Infrastructure Network System.

World Bank, (2001). Private Sector Development Strategy, Journal paper The World Bank, Washington DC.

Jasa Marga, (2001). Perkembangan Jal Tol di Indonesia, PT. Jasa Marga.

PIARC, (1999). Financing of Road Infrastructure Guide for New Methods of Financing and Public Privete Partnership, Directorate of Infrastructure Network System.

Djumirin, (1997). Private Sectors Investment in Tol Road Business Throught BOT System in Indonesia, Faculty of Economics, University of Indonesia.

LAPI ITB, (1996). Perhitungan Biaya Operasi Kendaraan, PT. Jasa Marga (Persero).

PT. Jasa Marga (Persero), (1995). Sejarah Perkembangan Tarif Tol Jalan Tol di Seluruh Indonesia, Divisi Manajemen Pengumpulan Tol. 
Pasific Consultant International (PCl), (1979). The Concultant Engineering Services for Jakarta Intra Urban Tollway, Phase I Report, Direktorat Jenderal Bina Marga, Departemen Pekerjaan Umum.

Wuestefeld N.H. \& Regan III E.J., (1981). Impact of Rate Increases on Toll Facilities, Traffic Quarterly, Vol. XXXV, No.4 . 